\title{
LAPAROSCOPIC OR CONVENTIONAL ABDOMINOPERINEAL EXTIRPATION IN LOW RECTAL CANCER
}

\author{
Gancho Kostov ${ }^{1}$, Rosen Dimov $^{1}$, Valentin Ivanov ${ }^{2}$, Dimcho Argirov ${ }^{1}$, Rangel Kunchev $^{2}$, \\ Veselin Marinov ${ }^{3}$, Dzhevdet Chakurov $^{3}$, Atanas Chapkunov, Maria Stoilova ${ }^{1}$, Boris Boev $^{2}$ \\ ${ }^{1}$ Department of Special Surgery, Faculty of Medicine, Medical University of Plovdiv \\ ${ }^{2}$ Department of Surgery, Kaspela University Hospital of Plovdiv \\ ${ }^{3}$ Department of Propedeutics of Surgical Diseases, Faculty of Medicine, \\ Medical University of Plovdiv, Plovdiv, Bulgaria
}

\begin{abstract}
INTRODUCTION: Laparoscopic abdominoperineal resection (LAPR) as a minimally invasive approach for the treatment of large rectal cancer is widely used. It has been proven to be technically feasible and safe with fewer complications and faster postoperative recovery than the open procedure. Our aim was to evaluate LAPR safety and feasibility as compared to the open procedure in large low rectal cancer.

PATIENTS AND METHODS: A total of 34 low rectal cancer patients who underwent open APR (OAPR) were matched with 42 patients who underwent LAPR in a one-to-one fashion between 2011 and 2014 in the Division of General Surgery, Kaspela University Hospital of Plovdiv.

RESULTS: Intraoperative parameters of LAPR were better than those of OAPR as followed: mean operation time (121.8 $\pm 47.8 \mathrm{~min}$ versus $152.1 \pm 49.2 \mathrm{~min})$, mean operative blood loss $(82 \pm 30.0 \mathrm{~mL}$ versus $120 \pm 35.0 \mathrm{~mL})$, mean total number of retrieved lymph nodes $(12 \pm 1$ versus $12 \pm 1.4)$, and percentage of surgical complications (12.3\% versus $15.1 \%)$. Laparoscopically treated patients showed significantly shorter postoperative analgesia (2.1 \pm 0.7 days versus $3.7 \pm 0.6$ days), earlier first flatus (36.3 \pm 7.9 hours versus $48.5 \pm 9.2$ hours), shorter urinary drainage (3.8 \pm 3.4 days versus $5.8 \pm 1.3$ days), and shorter hospital stay (6.2 \pm 1 days versus $8 \pm 2.0$ days). Local recurrence rate during a three-year period (in 3 versus 4 patients) and metachronous liver metastasis (in 5 versus 6 patients) were less common after LAPR than after OAPR.
\end{abstract}

CONCLUSION: The risks of APR-specific surgical complications such as perineal wound infection and parastomal hernia were comparable between the laparoscopic and open surgery groups. There were no significant differences regarding local recurrence and metachronous liver metastasis between these groups. Complication and locoregional recurrence rates in low large rectal cancer patients after laparoscopic and open were quite similar. Scr Sci Med 2017; 49(3): 22-26

Keywords: laparoscopic abdominoperineal resection, open abdominoperineal resection, low rectal cancer, intraoperative parameters, complications

Address for correspondence:

Gancho Kostov

Department of Special Surgery

Faculty of Medicine, Medical University of Plovdiv

15a Vasil Aprilov Blvd

Plovdiv, 4000, Bulgaria

e-mail: caspela@abv.bg

Received: August 21, 2017

Accepted: September 15, 2017

\section{INTRODUCTION}

Each year more than one million people worldwide develop colorectal cancer (CRC). This pathology comes third in the structure of malignant neoplasms worldwide and is one of the most common causes of death in both genders. CRC is the second most common malignancy among males (after lung 
Kostov, Dimov, Ivanov et al.

cancer and prior to the gastric one) and the third one among females (after breast and uterine cancers).

Bulgaria is in the middle of both morbidity and mortality rates worldwide. In 2010, rectal cancer cases are 201.7 per 100000 and anorectal cancer ones are 161.5 per 100000 (including the newly-registered 23.6 cases per 100000). CRC occupies the second place in the mortality structure for Bulgaria for men (of $13 \%$ ) and for women (of 15.5\%). In terms of gender, the morbidity shows a greater impact on men than on women and this feature is typical of all the countries in the world. Traced in dynamics, CRC morbidity rates in Bulgaria show an increase during the period from 1980 to 2010, with the crude indicators increasing by more than two times and the standardized ones - by nearly 1.6 times (1).

Following Heald's concept of total mesorectal excision (TME), it is imposed as a 'gold standard' in the treatment of malignant rectal tumours. TME principles are based on acute dissection under direct visual control in the embryonic avascular plan. The rectum is excised together with an intact mesorectum covered at the back and laterally by the mesorectal fascia with precise dissection and nerve preservation (2).

After the incursion of laparoscopic surgery it was established that it presents with all the advantages of the conventional colorectal surgery adding all the advantages of the mini-invasive approach (3).

Within a study comparing the efficacy of conventional and laparoscopic abdominoperineal resections in 381 patients, the incidence of regional relapses for a three-year period was $9.7 \%$ in the mini-invasive and $10.1 \%$ in the conventional surgery group. This difference was statistically insignificant (4). Ac-

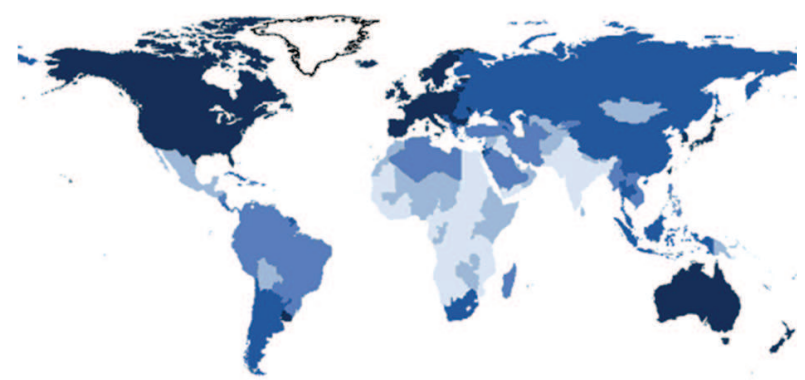

$=<4.6=<7.5=<12.5=<24.2=<42.1$

Fig. 1. CRC distribution according to incidence rate per 100000 (GLOBOCAN 2012, IARC) cording to the COLOR trial, a multicenter randomized study conducted in 1103 patients did not reveal any significant difference in the number of lymph nodes removed and sent for histological examination as well as between the radial and circumferential margins between the two groups.

In a study of 340 patients divided into laparoscopic and open group, estimated blood loss was less in the first group than in the second one (median $200.0 \mathrm{~mL}$; range $100.0-300.0 \mathrm{~mL}$ versus median $217.5 \mathrm{~mL}$; range, $150.0-400.0 \mathrm{~mL}$ ) in the open group; $\mathrm{p}=0.006)(5)$.

Numerous studies did not show any oncological difference in five-year survival rates and local relapses' incidence between conventional and laparoscopic rectal surgery when the latter was performed by an experienced surgeon $(4,6)$.

Our purpose was to evaluate the efficacy and the advantages of LAPR versus OAPR.

\section{PATIENTS AND METHODS}

The study included 34 patients with LAPR and 42 ones with OAPR regardless of the stage of the disease during the period between 2011 and 2015 in the Department of Surgery, Kaspela University Hospital of Plovdiv. Both types of surgery were performed according to the generally accepted oncological requirements. In the mini-invasive group, four trocars were used. We placed two $10 \mathrm{~mm}$ ports, the first paraumbillically and the second near Mc Burney point as well as two $5 \mathrm{~mm}$ trocars located in the region of the bisphinal and the anterior axillary line, respectively. We used the 'medial-to-lateral approach' with low ligation of the inferior mesenteric vessels. After complete specimen mobilization to the pelvic floor, we started the perineal part of the procedure, the proximal section of the specimen was done by endo GIA and the intestine was extracted as a permanent 'anus praeter'. The specimen was extracted perineally.

In the open group, the surgery started with a median laparotomy, after a meticulous inspection of the abdominal cavity to assess the tumor and the enclosure of the surgical field. It proceeded to mobilize the rectum, preferring the mobilization from lateral to medial again with low ligation of inferior mesenteric vessels. Beyond, the technique was overlapping in both groups. 


\section{RESULTS}

We established that Intraoperative parameters of LAPR were better than those of OAPR as followed: mean operation time $(121.8 \pm 47.8 \mathrm{~min}$ versus $152.1 \pm 49.2 \mathrm{~min})$, mean operative blood loss $(82 \pm 30.0$ $\mathrm{mL}$ versus $120 \pm 35.0 \mathrm{~mL}$ ), mean total number of retrieved lymph nodes ( $12 \pm 1$ versus $12 \pm 1.4)$, and percentage of early surgical complications (12.3\% versus $15.1 \%)$. Laparoscopically treated patients showed significantly shorter postoperative analgesia $(2.1 \pm 0.7$ days versus $3.7 \pm 0.6$ days), earlier first flatus ( $36.3 \pm 7.9$ hours versus $48.5 \pm 9.2$ hours), shorter urinary drainage (3.8 \pm 3.4 days versus $5.8 \pm 1.3$ days), and shorter hospital stay ( $6.2 \pm 1$ days versus $8 \pm 2.0$ days). Local recurrence rate during a three-year period (in 3 versus 4 patients) and metachronous liver metastasis (in 4 versus 5 patients) were less common after LAPR than after OAPR (Table 1).

In our study, the duration of laparoscopic-assisted perineal operations is significantly shorter, due to better visual performance especially in male patients with narrow pelvis and, last but not least, the rich experience gained in laparoscopic and, in particular, in colorectal laparoscopic surgery. These re- sults differ from the majority of publications available where the duration of the operative time is significantly higher in the mini-invasive interventions (7).

The complications in APR are demonstrated on Table 2.

Bleeding in our laparoscopic group is significantly lower than in the open one that is similar to most studies because of the good visualization and anatomical work in an acute manner (8).

Our study shows less need for analgesics in the early postoperative period, earlier passage recovery, shorter urinary drainage and hospital stay in the mini-invasive group. This data coincides with the literature available (9).

The incidence of complications in our study was $14.7 \%(n=5)$ in the laparoscopic and $16.6 \%(n=7)$ in the conventional group. Several randomized trials performed during the period between 2004 and 2009 did not differ concerning the incidence of postoperative complications between laparoscopic and conventional colorectal surgery $(10,11)$ while another publication showed a greater incidence of complications in the laparoscopic group (12). Conversion to

Table 1. Laparoscopic versus conventional APR

\begin{tabular}{lcc} 
& Laparoscopic group $\mathbf{n = 3 4}$ & Conventional group $\mathbf{n = 4 2}$ \\
Duration of surgery & $121.8 \mathrm{~min}$. & $151 \mathrm{~min}$. \\
Blood loss & $82 \pm 30.0 \mathrm{ml}$ & $120 \pm 35.0 \mathrm{ml}$ \\
Removed lymph nodes & $12 \pm 1$ & $13 \pm 1.4$ \\
Complications & $\mathrm{n}=5 / 14.7 \%$ & $\mathrm{n}=7 / 16.6 \%$ \\
Needs for analgetics & $2.1 \pm 0.7 \mathrm{~d}$ & $3.7 \pm 0.6 \mathrm{~d}$ \\
Appearance of flatulence & $36.3 \pm 7.9 \mathrm{~h}$ & $48.5 \pm 9.2 \mathrm{~h}$ \\
Days with PUC & $3.8 \pm 2.4 \mathrm{~d}$ & $5.8 \pm 2.3 \mathrm{~d}$ \\
Hospital stay & $6.2 \pm 1 \mathrm{~d}$ & $8 \pm 2.0 \mathrm{~d}$ \\
Local relapses within three years & $\mathrm{n}=3$ & $\mathrm{n}=4$ \\
Metacrhonic liver lesions & $\mathrm{n}=4$ & $\mathrm{n}=5$ \\
\hline \hline
\end{tabular}

Table 2. Complications in APR

\begin{tabular}{l|cc}
\hline Complications & Laparoscopic $\mathbf{n}=\mathbf{5}$ & Conventional $\mathbf{n}=\mathbf{7}$ \\
Bleeding from presacral vessels & $\mathrm{n}=2$ & $\mathrm{n}=2$ \\
Early postoperative ileus & $\mathrm{n}=3$ & $\mathrm{n}=2$ \\
Infection of the surgical wound/abdominal/ & $-\mathrm{n}=2$ & - \\
Infection of the perineal wound & $\mathrm{n}=1$ & - \\
Bleeding from a ports incision &
\end{tabular}


Kostov, Dimov, Ivanov et al.

open surgery was around $4.2 \%$ in literature data (13) that was similar to our results.

Twenty-five randomized trials (15) have reported a shorter hospital stay of LAPR patients as this statement overlaps with our own data. There is no statistically significant difference between both groups concerning the number of lymph nodes sent for histological analysis. According to many studies, the number of displaced and investigated lymph nodes in mini-invasive rectal surgery increases with the accumulated experience of the so-called 'learning curve effect' and in the presence of tumours in stages T3-T4 (16).

The comparison of long-term results, such as the incidence of local relapses in our study, showed three-year disease-free survival rates of $91.2 \%$ in the laparoscopic and $90.5 \%$ in the open group. These results are similar to other ones (12). According to some researchers, the lower frequency of local recurrences in mini-invasive rectal surgery is due to the lower operation trauma. This statement is not generally accepted because of the high incidence of port metastases, which, according to literary data, do not exceed $2,4 \%$.

\section{CONCLUSION}

Laparoscopic rectal oncologic surgery presents with better results such as shorter hospital stay, less need for analgesia, faster passage recovery, better patient's quality of life and oncologic results which are comparable to those of open surgery.

\section{REFERENCES}

1. National Cancer Registry of Bulgaria. Sofia, 2010 (in Bulgarian).

2. Heald RJ, Husband EM, Ryall RD. The mesorectum in rectal cancer surgery - the clue to pelvic recurrence? Br J Surg 1982;69(10):613-6.

3. Martel G, Boushey RP. Laparoscopic colon surgery: past, present and future. Surg Clin North Am. 2006;86(4):867-97.

4. Jayne DG, Guillou PJ, Thorpe H, Quirke P, Copeland J, Smith AM, et al.; UK MRC CLASICC Trial Group. Randomized trial of laparoscopic-assisted resection of colorectal carcinoma: 3-year results of the UK MRC CLASICC Trial Group. J Clin Oncol. 2007;25(21):3061-8. doi: 10.1200/JCO.2006.09.7758.
5. Kang SB, Park JW, Jeong SY, Nam BH, Choi HS, Kim DW, et al. Open versus laparoscopic surgery for mid or low rectal cancer after neoadjuvant chemoradiotherapy (COREAN trial): short-term outcomes of an open-label randomised controlled trial. Lancet Oncol. 2010;11(7):637-45. doi: 10.1016/ S1470-2045(10)70131-5.

6. Monson JR, Weiser MR, Buie WD, Chang GJ, Rafferty JF, Buie WD, et al.; Standards Practice Task Force of the American Society of Colon and Rectal Surgeons. Practice parameters for the management of rectal cancer (revised). Dis Colon Rectum. 2013;56(5):535-50. doi: 10.1097/ DCR.0b013e31828cb66c.

7. Jayne DG, Guillou PJ, Thorpe H, Quirke P, Copeland J, Smith AM, Heath RM, Brown JM; UK MRC CLASICC Trial Group. Randomized trial of laparoscopic-assisted resection of colorectal carcinoma: 3-year results of the UK MRC CLASICC Trial Group. J Clin Oncol 2007; 25: 3061-3068 [PMID: 17634484 DOI: 10.1200/JCO.2006.09.7758]

8. Lourenco T, Murray A, Grant A, McKinley A, Krukowski Z, Vale L. Laparoscopic surgery for colorectal cancer: safe and effective? - A systematic review. Surg Endosc. 2008;22(5):1146-60. doi: 10.1007/ s00464-007-9686-x

9. Rea JD, Cone MM, Diggs BS, Deveney KE, Lu KC, Herzig DO. Utilization of laparoscopic colectomy in the United States before and after the clinical outcomes of surgical therapy study group trial. Ann Surg. 2011;254(2):281-8. doi: 10.1097/ SLA.0b013e3182251aa3.

10. McKay GD, Morgan MJ, Wong SK, Gatenby AH, Fulham SB, Ahmed KW, et al.; South Western Sydney Colorectal Tumor Group. Improved short-term outcomes of laparoscopic versus open resection for colon and rectal cancer in an area health service: a multicenter study. Dis Colon Rectum. 2012;55(1):42-50. doi: 10.1097/ DCR.0b013e318239341f.

11. Buunen M, Veldkamp R, Hop WC, Kuhry E, Jeekel J, Haglind E, et al.; Colon Cancer Laparoscopic or Open Resection Study Group Survival after laparoscopic surgery versus open surgery for colon cancer: long-term outcome of a randomised clinical trial. Lancet Oncol. 2009;10(1):44-52. doi: 10.1016/ S1470-2045(08)70310-3.

12. Guillou PJ, Quirke P, Thorpe H, Walker J, Jayne DG, Smith AM, Heath RM, Brown JM; MRC CLASICC trial group. Short-term endpoints of 
Laparoscopic or conventional abdominoperineal extirpation in low rectal cancer

conventional versus laparoscopic-assisted surgery in patients with colorectal cancer (MRC CLAS-

ICC trial): multicentre, randomised controlled trial. Lancet. 2005;365(9472):1718-26. doi: 10.1016/ S0140-6736(05)66545-2.

13. Lacy AM, García-Valdecasas JC, Delgado S, Castells A, Taurá P, Piqué JM, et al. Laparoscopy-assisted colectomy versus open colectomy for treatment of non-metastatic colon cancer: a randomised trial. Lancet. 2002;359(9325):2224-9. doi: 10.1016/ S0140-6736(02)09290-5.

14. Braga M, Pecorelli N, Frasson M, Vignali A, Zuliani W, Di Carlo V. Long-term outcomes after laparoscopic colectomy. World J Gastrointest Oncol. 2011;(3):43-8. doi: 10.4251/wjgo.v3.i3.43.

15. Weeks JC, Nelson H, Gelber S, Sargent D, Schroeder G; Clinical Outcomes of Surgical Therapy (COST) Study Group. Short-term quality-of-life outcomes following laparoscopic-assisted colectomy vs open colectomy for colon cancer: a randomized trial. JAMA. 2002;287(3):321-8. doi: 10.1001/ jama.287.3.321.

16. Prakash K, Kamalesh NP, Pramil K, Vipin IS, Sylesh A, Jacob M. Does case selection and outcome following laparoscopic colorectal resection change after initial learning curve? Analysis of 235 consecutive elective laparoscopic colorectal resections. J Minim Access Surg. 2013;9(3):99-103. doi: 10.4103/0972-9941.115366. 